\title{
The Potential of the LFR and the ELSY Project
}

L. Cinotti, C. F. Smith, J. J. Sienicki, H. Ait Abderrahim, G. Benamati, G. Locatelli, S. Monti, H. Wider, D. Struwe, A. Orden, I. S. Hwang

April 4, 2007

ICAPP 2007

Nice, France

May 13, 2007 through May 18, 2007 
This document was prepared as an account of work sponsored by an agency of the United States government. Neither the United States government nor Lawrence Livermore National Security, LLC, nor any of their employees makes any warranty, expressed or implied, or assumes any legal liability or responsibility for the accuracy, completeness, or usefulness of any information, apparatus, product, or process disclosed, or represents that its use would not infringe privately owned rights. Reference herein to any specific commercial product, process, or service by trade name, trademark, manufacturer, or otherwise does not necessarily constitute or imply its endorsement, recommendation, or favoring by the United States government or Lawrence Livermore National Security, LLC. The views and opinions of authors expressed herein do not necessarily state or reflect those of the United States government or Lawrence Livermore National Security, LLC, and shall not be used for advertising or product endorsement purposes. 


\title{
The Potential of the LFR and the ELSY Project
}

\author{
L. Cinotti (Del Fungo Giera Energia), C. F. Smith (LLNL), J. J. Sienicki, (ANL) \\ H. Aït Abderrahim (SCK-CEN), G. Benamati (ENEA), G. Locatelli (Ansaldo Nucleare), \\ S. Monti (ENEA), H. Wider (JRC/IE), D. Struwe (FZK), \\ A. Orden (Empresarios Agrupados), I.S. Hwang (NUTRECK-KESRI) \\ Tel:+390185738721, Fax:+390276395560,Email:luciano.cinotti@delfungogieraenergia.com
}

\begin{abstract}
This paper presents the current status of the development of the Lead-cooled Fast Reactor (LFR) in support of Generation IV (GEN IV) Nuclear Energy Systems.

The approach being taken by the GIF plan is to address the research priorities of each member state in developing an integrated and coordinated research program to achieve common objectives, while avoiding duplication of effort. The integrated plan being prepared by the LFR Provisional System Steering Committee of the GIF, known as the LFR System research Plan (SRP) recognizes two principal technology tracks for pursuit of LFR technology:

- a small, transportable system of 10-100 MWe size that features a very long refueling interval,

- a larger-sized system rated at about $600 \mathrm{MWe}$, intended for central station power generation and waste transmutation

This paper, in particular, describes the ongoing activities to develop the Small Secure Transportable Autonomous Reactor (SSTAR) and the European Lead-cooled SYstem (ELSY), the two research initiatives closely aligned with the overall tracks of the SRP and outlines the Proliferation-resistant Environment-friendly Accident-tolerant Continual \& Economical Reactors (PEACER) conceived with particular focus on burning/transmuting of long-living TRU waste and fission fragments of concern, such as Tc and I.

The current reference design for the SSTAR is a 20 MWe natural circulation pool-type reactor concept with a small shippable reactor vessel. Specific features of the lead coolant, the nitride fuel containing transuranics, the fast spectrum core, and the small size combine to promote a unique approach to achieve proliferation resistance, while also enabling fissile selfsufficiency, autonomous load following, simplicity of operation, reliability, transportability, as well as a high degree of passive safety. Conversion of the core thermal power into electricity at a high plant efficiency of $44 \%$ is accomplished utilizing a supercritical carbon dioxide Brayton cycle power converter.

The ELSY reference design is a 600 MWe pool-type reactor cooled by pure lead. This concept has been under development since September 2006, and is sponsored by the Sixth Framework Programme of EURATOM. The ELSY project is being performed by a consortium consisting of twenty organizations including seventeen from Europe, two from Korea and one from the USA. ELSY aims to demonstrate the possibility of designing a competitive and safe fast critical reactor using simple engineered technical features while fully complying with the Generation IV goal of minor actinide (MA) burning capability.

The use of a compact and simple primary circuit with the additional objective that all internal components be removable, are among the reactor features intended to assure competitive electric energy generation and long-term investment protection. Simplicity is expected to reduce both the capital cost and the construction time; these are also supported by the compactness of the reactor building (reduced footprint and height). The reduced footprint would be possible due to the elimination of the Intermediate Cooling System, the reduced elevation the result of the design approach of reduced-height components.
\end{abstract}

\section{INTRODUCTION}

The Generation IV (GEN IV) Technology Roadmap [1], prepared by GIF member countries, identified the six most promising advanced reactor systems and related fuel cycle and the R\&D necessary to develop these concepts for potential deployment. Among the promising reactor technologies being considered by the GIF, the LFR has been identified as a technology with great potential to meet the needs for both remote sites and central power stations.

In the GEN IV technology evaluations, the LFR system was top-ranked in sustainability because it uses a closed fuel cycle, and in proliferation resistance and physical protection because it employs a long-life core. It was rated good in safety and economics. The safety was considered to be enhanced by the choice of a relatively inert coolant. The LFR was primarily envisioned for missions in electricity and hydrogen production and 
actinide management. Given its R\&D needs for fuel, materials, and corrosion control, the LFR system was estimated to be deployable by 2025 . The LFR system features a fast-neutron spectrum and a closed fuel cycle for efficient conversion of fertile uranium. The LFR can also be used as a burner of all actinides from spent fuel and as a burner / breeder with thorium matrices.

The GIF LFR Provisional System Steering Committee has prepared a draft of the System Research Plan (SRP) for the Lead-Cooled Fast Reactor [2] with molten lead as the reference coolant and lead-bismuth as backup option. Figure 1 below illustrates the basic approach being recommended in the LFR SRP. It portrays the dual track viability research program with convergence to a single, combined demonstration facility (demo) leading to eventual deployment of both types of systems.

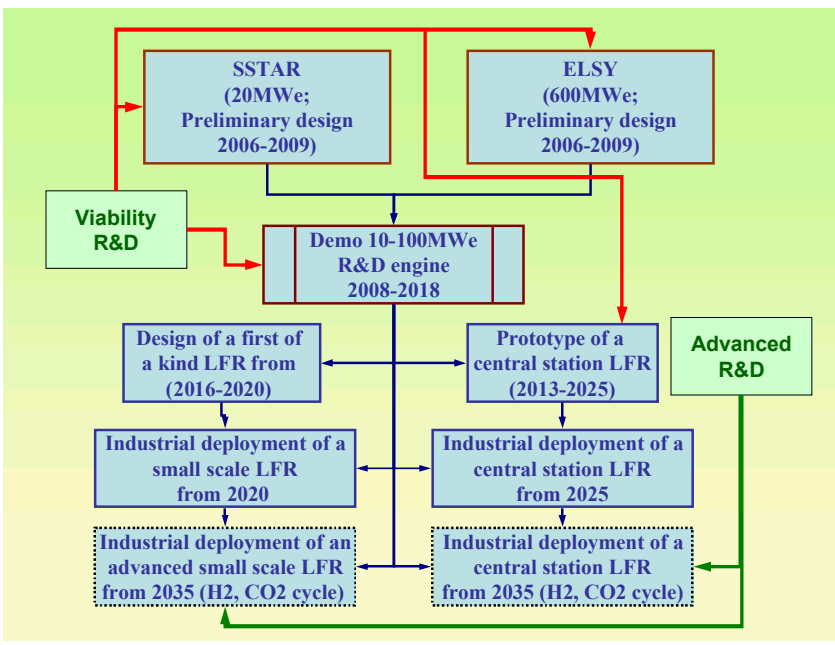

Fig.1. LFR SRP Conceptual Framework

This approach consists of the design of a small transportable system of 10-100 MWe size that features a very long refuelling interval, and of a larger system, rated at about $600 \mathrm{MWe}$, intended for central station power generation. Following the successful operation of the demo around the year 2018, a prototype development effort is expected for the central station LFR leading to industrial deployment at the horizon of 2025. In the case of the small transportable (SSTAR) option the development of a first of a kind unit in the period 2016-2020 is foreseen. Because of the small size of the SSTAR it is expected that the main features can be established during the demo phase, and that it will be possible to move directly to industrial deployment without going to the prototype phase.

The design of the industrial prototype of the central station LFR and that of the first of a kind SSTAR should be carried out in parallel to the construction of the Demo and planned in such a way as to start construction as soon as beginning of the Demo operation at full power has given the main assurances of the viability of this new technology.

At present the main ongoing activities in the countries that are members of the GIF are:

- the development of the Small Secure Transportable Autonomous Reactor (SSTAR) in U.S.;

- the development of the Battery Optimized Reactor Integral System (BORIS) [3] and the Proliferation-resistant Environment-friendly Accident-tolerant Continual-energy Economical Reactors (PEACERs) [4], in the Republic of Korea (ROK). BORIS is a 23 MWth multi-purpose fast reactor designed to satisfy distributed energy demands, to provide inherent safety using $\mathrm{Pb}$ as the coolant, and to improve economic efficiency by employing a supercritical $\mathrm{CO}_{2}$ Brayton cycle [5].

. the study of small LBE cooled reactors in Japan and particularly a LBE-cooled 4S (Super safe, small and simple reactor) and Steam Lift Pump Type LBE Cooled Reactors.

- the development of ELSY (acronym of European Lead cooled System) in Europe.

Moreover, outside the countries that are current members of GIF, the Institute of Physics and Power Engineering (IPPE), OKB Gidropress, and Atomenergoproekt [6] have developed SVBR-75/100, a LBE-cooled modular fast reactor having a power range of 75 to $100 \mathrm{MWe}$, and the Russian Research and Development Institute of Power Engineering (NIKIET) has developed the BREST lead-cooled fast reactor concept and the associated fuel cycle [7], an innovative approach to nuclear waste management in a closed fuel cycle.

SSTAR, PEACERs and ELSY are described in more detail here below.

\section{THE SMALL TRANSPORTABLE SYSTEM}

The Small Secure Transportable Autonomous Reactor (SSTAR) is being developed under the U.S. Department of Energy Generation IV Nuclear Energy Systems Initiative as a small reactor for international deployment in non-fuel cycle states or in remote, isolated sites in fuel cycle states, as appropriate. SSTAR also incorporates concepts that are reflected in the Global Nuclear Energy Partnership (GNEP) to develop systems suitable for deployment anywhere in the world. Two key technical aspects of the envisioned small LFR are the use of lead $(\mathrm{Pb})$ as coolant and a longlife sealed or cartridge-core architecture in a small, modular system. SSTARs offer an alternative approach to actinide management by "storing" actinides in long life (e.g., 15- to 30-year) cores in fissile self-sufficient operating power reactors. Thus, instead of burning minor actinides (MAs) in Advanced Burner Reactors, the MAs are incorporated into a comparable number of SSTARs, which return the fissile resources at the end of the core lifetime. Small fast reactor converters for international 
deployment in non-fuel cycle states for the purpose of meeting future global energy demands have thus been part of the U.S. LFR work since its inception. The focus of LFR work under Generation IV has been the assessment of viability and development of a pre-conceptual design for the SSTAR LFR concept. The reference design for SSTAR is a small (20 MWe/45 MWt, that can be scaled up to 181 $\mathrm{MWe} / 400 \mathrm{MWt}$ )) natural circulation fast reactor plant for international deployment incorporating proliferation resistance for deployment in partner states, fissile selfsufficiency for efficient utilization of uranium resources, autonomous load following suitable for small or immature electric grids, and a high degree of passive safety. Inherent thermo-structural feedbacks impart walk-away passive safety, while the use of a sealed cartridge core with a 15year or longer cycle time between refueling imparts strong proliferation resistance.

SSTAR does not incorporate an intermediate heat transport circuit. This is a simplification possible with $\mathrm{Pb}$ coolant and $\mathrm{CO}_{2}$ working fluid. Figure 2 provides a sketch of the currently envisioned SSTAR small LFR system concept and operating parameters. The SSTAR core (Fig. 3) is an open lattice of large diameter ( $2.5 \mathrm{~cm} \mathrm{OD)}$ fuel pins on a triangular pitch $(\mathrm{p} / \mathrm{d}=1.185)$ that does not consist of removable fuel assemblies. The fuel pins are permanently attached to an underlying support plate. This configuration restricts access to fuel and eliminates traditional instantaneous fuel assembly inlet blockage accident initiators.

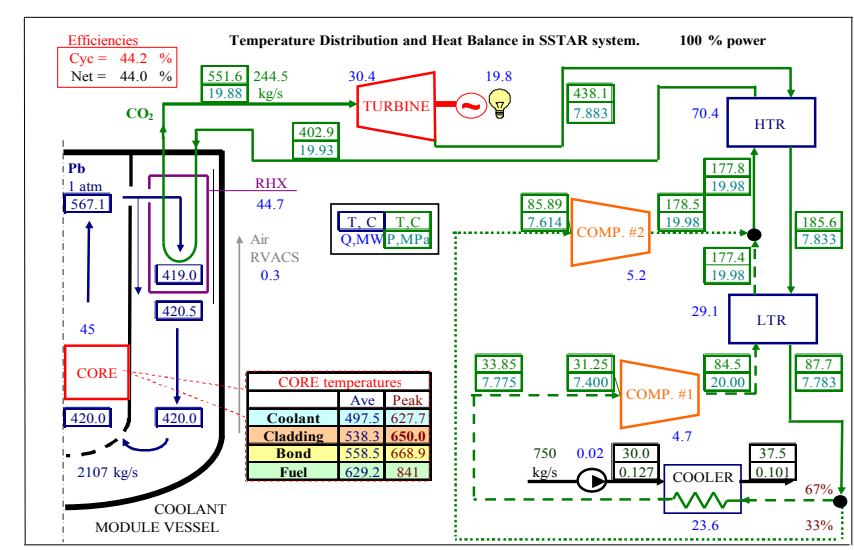

Fig. 2. SSTAR Preliminary Design Concept and Operating Parameters with $\mathrm{S}-\mathrm{CO}_{2}$ Brayton Cycle Energy Converter

The compact active core, which is $1.22 \mathrm{~m}$ in diameter by $0.976 \mathrm{~m}$ in height is removed as a single cassette during refueling or plant refurbishment and replaced by a fresh core. The active core diameter is selected to minimize the burn-up reactivity swing over the 30-year core lifetime. The power level of $45 \mathrm{MWt}$ is conservatively chosen to limit the peak fluence on the cladding to $4 \times 10^{23}$ neutrons $/ \mathrm{cm}^{2}$, which is the maximum exposure for which HT9 cladding has been irradiated. The core (Fig. 3) incorporates two low enrichment zones in the core central region, which helps to reduce the burn-up reactivity swing. Three driver enrichment zones reduce the peak-to-average power. Primary and secondary sets of control rods are uniformly dispersed throughout the active core; primary rods are shown in magenta and secondary rods in blue in Fig. 3. The radial reflector consists of an annular "box" containing 50 volume \% stainless steel rods and 50 volume $\% \mathrm{~Pb}$ with a small flowrate of $\mathrm{Pb}$ to remove the small power deposition in the reflector. Stainless steel is necessary to shield the reactor vessel from neutrons reducing the fluence at the reactor vessel.

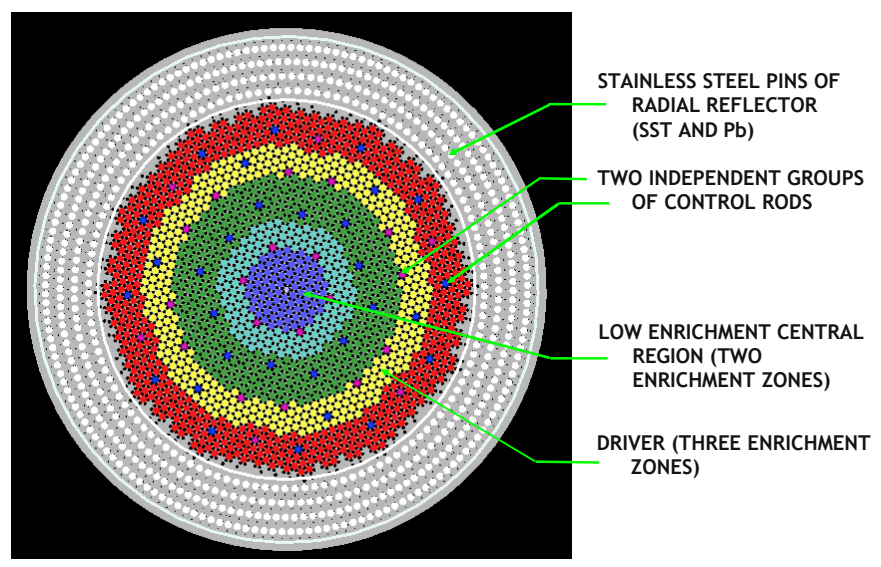

Fig. 3. SSTAR 30-Year Core (All Fuel Pins Are Shown).

The core design meets the requirements of a 15- to 30year-life core with minimal burnup reactivity swing and selection of fuel, support, and restraint configurations providing reactivity feedback coefficients for Doppler, fuel axial expansion, coolant density, and core radial expansion imparting autonomous load following and passive shutdown behavior. Passive safety response can be readily designed into the reactor core and plant based on the inherent safety features of $\mathrm{Pb}$ coolant, transuranic nitride fuel, the fast spectrum core, natural circulation heat transport, current experience, and passive safety design principles. Magnitudes of feedback coefficients and integral behavior of a reactor plant shall be verified by means of transient tests conducted using the demo. 


\section{PEACER}

The Proliferation-resistant, Environment-friendly, Accident-tolerant Continual \& Economical Reactor (PEACER) is being developed at the Nuclear Transmutation Energy Research Center of Korea (NUTRECK) aiming at avoiding spent nuclear fuel disposal in geological formations and at assuring international control on proliferation-sensitive nuclear materials. Both long-living TRU waste and fission products including Tc and I can be stabilized in its duplex fast-epithermal neutron spectrum and electricity can be simultaneously generated. [4]

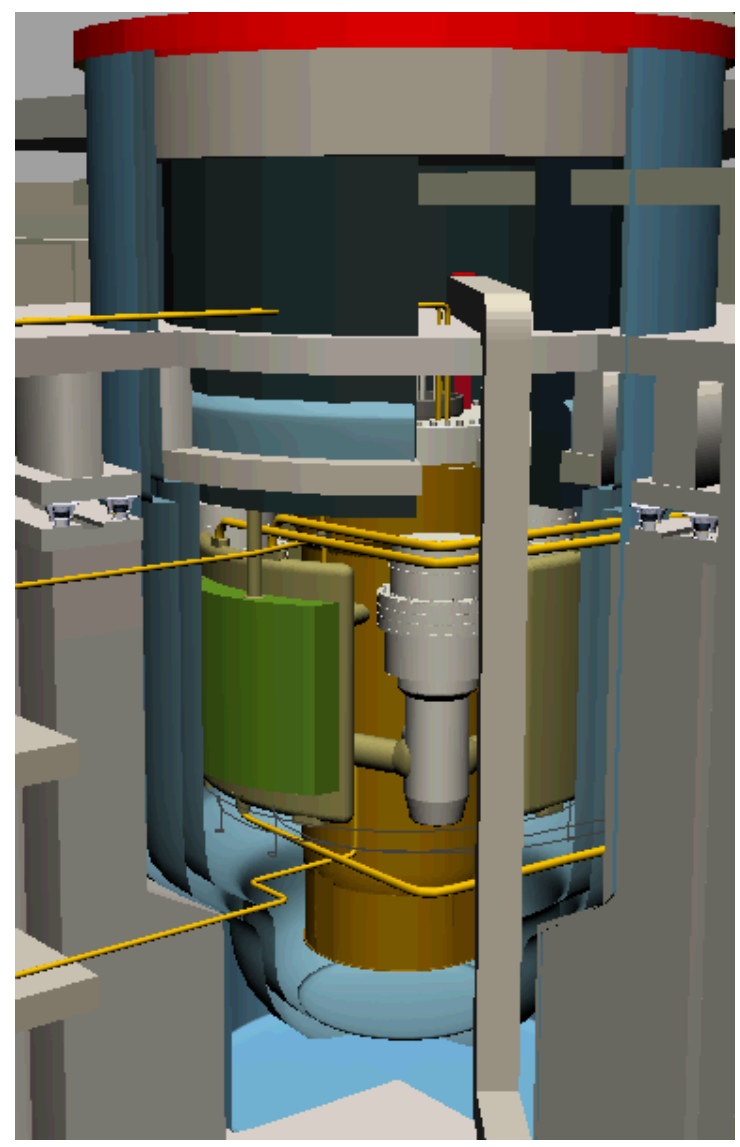

Fig. 4. 3D CAD Drawing of PEACER-300 MWe

The Accident-tolerance requirement mandated development of an Reactor Auxiliary Vessel Air Cooling System (RVACS). A new passive water cooling system for the reactor vessel outer wall has been introduced as an innovative design that allows for system scaleup from 300 MWe up to 1200 MWe with Accident-tolerance. Analyses of the final waste disposal site performance have shown that the vitrified waste from pyrochemical decontamination processes of PEACER can be qualified as low-level waste. Final design parameters for PEACER-300 MWe are shown in Table I.

Table I. Main Design Parameters of PEACER-300

\begin{tabular}{|c|c|}
\hline Rated Power & $850 \mathrm{MWt}(300 \mathrm{MWe})$ \\
\hline Coolant & $\mathrm{Pb}-\mathrm{Bi}(45-55 \%)$ eutectic \\
\hline Scram System & $\mathrm{B}_{4} \mathrm{C}$ Assemblies \\
\hline In core Management & 3 Batch Annual Reload \\
\hline Fuel Cycle Strategy & $\begin{array}{l}\text { Full Actinide Recycle } \\
\text { Co-located Pyrochemical } \\
\text { Facility }\end{array}$ \\
\hline Capacity Factor & $90 \%$ \\
\hline Average Power Density & $205 \mathrm{MW} / \mathrm{m} 3$ \\
\hline Fuel Composition & $\begin{array}{l}\text { U-TRU-Zr (57-32-11 Wt. \%) } \\
3 \text { Enrichment Zoning } \\
\text { Smeared Density : } 67 \%\end{array}$ \\
\hline Fuel Assembly & $\begin{array}{l}\text { PWR Type Open Lattice } \\
\text { (Square Array without } \\
\text { Wrapper) }\end{array}$ \\
\hline Core Shape & $\begin{array}{c}\text { Flat (Pancake Design) } \\
50 \mathrm{~cm} \mathrm{H} \mathrm{X} 500 \mathrm{~cm} \mathrm{D}\end{array}$ \\
\hline
\end{tabular}

Key-technologies for successful PEACER deployment include transmutation reactor core neutron spectrum zoning (fast and epi-thermal), high decontamination pyrochemical processes, natural circulation under accidental conditions, advanced $\mathrm{Pb}-\mathrm{Bi}$ coolant technology for system life/toxicity management and overhung structural design with $3 \mathrm{D}$ seismic isolators. In order to effectively coordinate design parameters with sophisticated technological interactions, a new powerful design approach, designated as Solver-Interfaced Virtual Reality (SIVR) has been worked out at NUTRECK. The new Solver-Interfaced Virtual Reality tool tailored for PEACER development, PEACER-SIVR, has evolved from CATIA and free Virtual Reality Modeling Language (VRML) such that 3-D CAD data can be directly used for the input preparation of nuclear solver codes and for 3-D visualization of outputs, facilitating design changes (Fig.4).

The HELIOS (Heavy Eutectic liquid metal Loop for the Integral test of Operability and Safety of PEACER) has been developed by scaling the PEACER-300 design of Table I. Operability, natural circulation capability, and materials corrosion resistance have been successfully tested. As a result, the reliability, chemical stability, safety, and economy of PEACER-300 have been demonstrated to 
warrant continued R\&D towards a demonstration reactor design development.

\section{ELSY}

A major step in favor of the LFR occurred, when EURATOM decided to fund ELSY (the acronym for the European Lead cooled System) - a Specific Targeted Research Project of the 6th European Framework Program (PP6) - proposed to investigate the economical feasibility of using critical reactors for nuclear waste transmutation.

Since September 2006, a consortium of twenty organizations including seventeen from Europe, two from ROK and one from United States (Table II) have been pursuing the development of ELSY, a lead-cooled, critical reactor of $600 \mathrm{MWe}$ power [8]; the project is scheduled to last three years.

TABLE II

Organizations involved in the ELSY project

\begin{tabular}{|c|c|c|}
\hline Participant organisation & $\begin{array}{l}\text { Short } \\
\text { name }\end{array}$ & Country \\
\hline Ansaldo Energia S.p.A & $\begin{array}{l}\text { ANSALD } \\
\mathrm{O}\end{array}$ & Italy \\
\hline $\begin{array}{l}\text { AGH, Akademia Górniczo- } \\
\text { Hutnicza }\end{array}$ & $\mathrm{AGH}$ & Poland \\
\hline $\begin{array}{l}\text { Centro Elettrotecnico } \\
\text { Sperimentale Italiano }\end{array}$ & CESI & Italy \\
\hline $\begin{array}{l}\text { Inter Universities Consortium for } \\
\text { Nuclear Technological Research }\end{array}$ & CIRTEN & Italy \\
\hline $\begin{array}{l}\text { Centre National de la Recherche } \\
\text { Scientifique }\end{array}$ & CNRS & France \\
\hline $\begin{array}{l}\text { Empresarios Agrupados } \\
\text { Internacional S.A. }\end{array}$ & EA & Spain \\
\hline Electricité de France & EDF & France \\
\hline $\begin{array}{l}\text { Ente Per Le Nuove Tecnologie, } \\
\text { L'energia e L'ambiente }\end{array}$ & ENEA & Italy \\
\hline $\begin{array}{l}\text { Forschungszentrum Karlsruhe } \\
\text { GmbH }\end{array}$ & FZK & Germany \\
\hline Institute for Nuclear Research & INR & Romania \\
\hline $\begin{array}{l}\text { European Commission, Joint } \\
\text { Research Centre }\end{array}$ & JRC & Europe \\
\hline $\begin{array}{l}\text { Royal Institute of Technology- } \\
\text { Stockholm }\end{array}$ & KTH & Sweden \\
\hline $\begin{array}{l}\text { Nuclear Research and } \\
\text { Consultancy Group } \\
\end{array}$ & NRG & Netherlands \\
\hline $\begin{array}{l}\text { Ustav jaderneho vyzkumu Rez, } \\
\text { a.s. (Nuclear Research Institute } \\
\text { Rez, plc.) }\end{array}$ & UJV & $\begin{array}{l}\text { Czech } \\
\text { Republic }\end{array}$ \\
\hline Paul Scherrer Institut & PSI & Switzerland \\
\hline $\begin{array}{l}\text { Studiecentrum voor } \\
\text { Kernenergie•Centre d'Etude de } \\
\text { l'énergie Nucléaire }\end{array}$ & $\mathrm{SCK} \cdot \mathrm{CEN}$ & Belgium \\
\hline Seoul National University & SNU & Korea \\
\hline Del Fungo Giera Energia S.p.A. & DEL & Italy \\
\hline $\begin{array}{l}\text { Massachusetts Institute of } \\
\text { Technology }\end{array}$ & MIT & USA \\
\hline Korea Electrical Engineering and & KESRI & Korea \\
\hline
\end{tabular}

Science Research Institute

The ELSY project aims at demonstrating the possibility to design a competitive and safe Lead-cooled fast power reactor using simple engineered features. This prospect is appealing also to private investors who have offered to participate in the initiative. This would create the conditions for advancing the ELSY activity even beyond the current sponsorship under Euratom's FP6.

The use of compact, in-vessel steam generators and a simple primary circuit with all internals possibly being removable are among the reactor features needed for competitive electric energy generation and long-term protection of investment. The tentative parameters of ELSY are specified in Table III.

To meet the technological needs of the ELSY project, it is important to capitalize on the strong synergy with two other two European initiatives, "The Integrated Infrastructure Initiative VELLA," which is devoted to the dissemination of knowledge in the field of lead technology, and the "Integrated Project EUROTRANS."

\section{IV.A. Plant power}

The ELSY power plant is tentatively sized at 600 MWe because only plants of the order of several hundreds MWe are expected to be economically affordable on the existing, well-interconnected grids of Europe. The possibly adverse effect of the high density of lead can be mitigated by more compact solutions and improvement of the design of the Reactor Vessel support system, i.e. the use of seismic isolators for a seismic-resistant design. Preliminary results of the reactor vessel and supports stress analysis indicate that an LFR larger than a medium-size plant is potentially feasible.

\section{IV.B. Coolant}

A large experience base exists on LBE in Russia [6] and elsewhere [8-11]. Since lead is much more abundant (and less expensive) than bismuth, in case of deployment of a large number of reactors, pure lead as coolant offers enhanced sustainability. Furthermore, the use of lead strongly reduces the production of the highly radioactive, and hence decay-heat generating polonium in the coolant with respect to LBE. These are the main reasons for selecting lead as primary coolant for ELSY.

Operation at a higher minimum temperature, required by the use of pure lead, would be necessary also in the case of LBE to improve plant efficiency and to avoid excessive embrittlement of structural material subjected to fast neutron flux at low temperature.

The risk of lead freezing is reduced by the choice of a pool-type configuration. 
TABLE III

Tentative parameters of the ELSY plant

\begin{tabular}{|c|c|}
\hline $\begin{array}{r}\text { Plant } \\
\text { Characteristic }\end{array}$ & Tentative Plant Parameters \\
\hline Power & $600 \mathrm{MWe}$ \\
\hline Thermal efficiency & $40 \%$ \\
\hline Primary coolant & Pure lead \\
\hline Primary system & Pool type, compact \\
\hline $\begin{array}{l}\text { Primary coolant } \\
\text { circulation (at power) }\end{array}$ & Forced \\
\hline $\begin{array}{l}\text { Primary system pressure } \\
\text { loss (at power) }\end{array}$ & $\sim 1,5$ bar \\
\hline $\begin{array}{l}\text { Primary coolant } \\
\text { circulation for DHR }\end{array}$ & Natural circulation + Pony motors \\
\hline Core inlet temperature & $\sim 400^{\circ} \mathrm{C}$ \\
\hline Core outlet temperature & $\sim 480^{\circ} \mathrm{C}$ \\
\hline Fuel & $\begin{array}{l}\text { MOX with consideration also of } \\
\text { nitrides and dispersed minor } \\
\text { actinides }\end{array}$ \\
\hline Fuel handling & $\begin{array}{l}\text { ELSY will seek innovative } \\
\text { solutions }\end{array}$ \\
\hline Fuel cladding material & T91 (aluminized) \\
\hline $\begin{array}{l}\text { Fuel cladding } \\
\text { temperature (max) }\end{array}$ & $\sim 550^{\circ} \mathrm{C}$ \\
\hline Main vessel & $\begin{array}{l}\text { Austenitic stainless } \\
\text { hanging, short-height } \sim 10 \mathrm{~m} \text {; } \\
\text { diameter } \sim 12 \mathrm{~m}\end{array}$ \\
\hline Safety vessel & Anchored to the reactor pit \\
\hline Steam generators & $\begin{array}{l}\mathrm{N}^{\circ} 8 \text {, integrated in the main } \\
\text { vessel }\end{array}$ \\
\hline Secondary cycle & $\begin{array}{l}\text { Water-supercritical steam at } 240 \\
\text { bar, } 450^{\circ} \mathrm{C}\end{array}$ \\
\hline Primary pumps & $\begin{array}{l}\mathrm{N}^{\circ} 4 \text {, mechanical, in the hot } \\
\text { collector }\end{array}$ \\
\hline Internals & Removable \\
\hline Inner vessel & Cylindrical \\
\hline Hot collector & Small-volume, above the core \\
\hline Cold collector & $\begin{array}{l}\text { Annular, outside the inner vessel, } \\
\text { free level higher than free level of } \\
\text { hot collector }\end{array}$ \\
\hline DHR coolers & $\begin{array}{l}\mathrm{N}^{\circ} 4 \text {, immersed in the cold } \\
\text { collector }+ \text { a Reactor Vessel Air } \\
\text { Cooling System between reactor } \\
\text { vessel and safety vessel. }\end{array}$ \\
\hline Seismic design & $\begin{array}{l}2 \mathrm{D} \text { isolators supporting the } \\
\text { reactor building }\end{array}$ \\
\hline
\end{tabular}

IV.C. Coolant circulation
The choice of a large reactor power suggests the use of forced circulation to shorten the reactor vessel, thereby avoiding excessive coolant mass and alleviating mechanical loads on the reactor vessel.

Thanks to the favorable neutronic characteristics of lead as coolant, the fuel rods of a lead-cooled reactor, similarly to LWRs, can be spaced further apart than in the case of sodium as a coolant, resulting in a lower pressure drop across the core. As a consequence, in spite of the higher density of lead, the needed pump head can be kept low (on the order of one to two bars) with a reduced requirement for pumping power.

\section{IV.D. Decay heat removal}

According to the predicted low primary system pressure loss and the favorable thermodynamic characteristics of lead, decay heat can be removed with lead in natural circulation in the primary system.

A simple system for decay heat removal is the Reactor Vessel Air Cooling System (RVACS), which consists basically of an annular pipe bundle of U-pipes arranged in the reactor pit with atmospheric air flowing pipe-side in natural circulation (Fig. 5).

RVACS is a passive system, but its use without other systems can only be considered for small-size reactors since the vessel outer surface is relatively large in comparison with the reactor power. In the case of ELSY, the RVACS performance is sufficient only in the long term (after about one month after shut down) and an additional four loops are needed equipped with coolers immersed in the primary system.

Because of the greater complexity, the in-vessel systems will result in a lower reliability than the simple RVACS. Stringent safety requirements will be achieved by redundancy and diversification.

A Reactor Pit Cooling System (RPCS) is additionally included for use during in-service inspection of the reactor vessel.

\section{IV.E. Thermal cycle}

A possible primary-side thermal cycle of $400^{\circ} \mathrm{C} / 480^{\circ} \mathrm{C}$ in lead, without an Intermediate Cooling System, offers reduced risk of steel creep and milder thermal transients, while providing a thermal efficiency above $40 \%$ with a supercritical Rankine steam cycle.

The reactor vessel is designed to operate at the cold temperature of $400^{\circ} \mathrm{C}$, which would be a safe condition even if oxygen control in the melt were temporarily lost. All reactor internals will have to operate in a temperature regime where it is necessary to rely on oxygen control, whereas fuel cladding could be surface-treated (aluminization seems to be a promising route) for a greater 
safety margin. Increasing the core outlet temperature to about $550^{\circ} \mathrm{C}$, as for the case of the SFR, would create an unjustified technological risk without any guarantee of technological success in the timeframe indicated by GIF. An improved primary-side thermal cycle at higher core outlet temperature could be adopted in the longer term, as new materials become available.

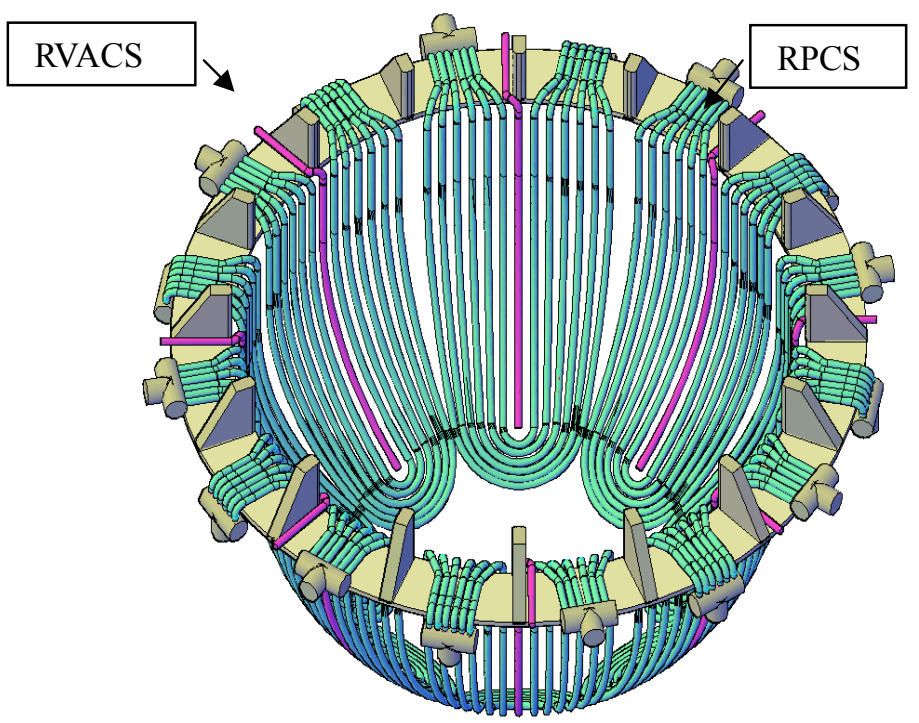

Fig. 5. RVACS and RPCS pipe bundle, schematic layout

The primary side thermal cycle is consistent with a secondary side water-supercritical steam at 240 bar, $450^{\circ} \mathrm{C}$ providing thermal efficiency above $40 \%$.

\section{IV.F. Primary System}

Figure 6 shows the cylindrical inner vessel concept, an example of scheme under evaluation as a starting point for the primary system design of ELSY (RVACS and RPCS are not shown).

The steam generator (SG) and primary pump (PP) assembly, consisting of two SG Units (SGUs) and one PP arranged between the SGUs and casing, is an integral part of the primary loop, i.e. from PP suction to SGU exit. Hot lead is pumped into the pool above the PP and SGU and driven shell-side downwards through the SGU tube bundle into the cold pool. The free level of the hot pool inside the casing is higher than the free level of the cold pool outside that is higher, in turn, than the free level of the hot pool above the core enclosed by the inner vessel.
A free level difference of cold and hot collectors at normal operating condition of only $1-2 \mathrm{~m}$ is sufficient to feed the core, eliminating the complicated, pressurized core feed system (Liposo and Sommier, in French) typical of the pool-type, sodium-cooled reactors.

Simplification of the internals will offer the possibility of removable in-vessel components, a provision for investment protection. In spite of the identified advantages of this scheme, design improvements remain to be developed at least to make the primary system more tolerant to Steam Generator Tube Rupture (SGTR) accidents.

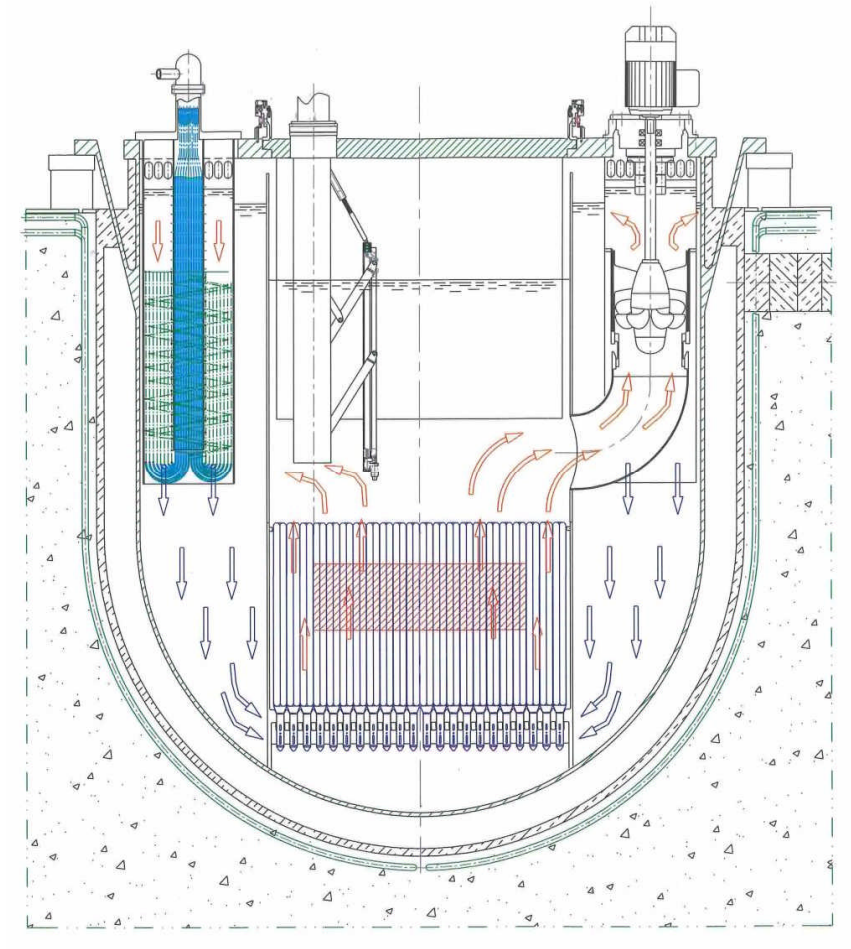

Fig. 6. Preliminary scheme of the ELSY Reactor

\section{IV.G. Reactor Building}

Compactness of the reactor building is the result of reduced footprint and height. The reduced footprint would be the consequence of the elimination of the Intermediate Cooling System, the reduced elevation the result of forced circulation and the design approach of reduced-height components.

\section{THE LFR CAN MEET THE FOUR GOAL AREAS AND EIGHT SPECIFIC GOALS OF GENERATION IV}


The members of the Generation IV International Forum (GIF) Provisional System Steering Committee (PSSC) have evaluated technology options and support the LFR based on its promise in meeting the Generation IV objectives. In particular, the GIF PSSC members have evaluated the two selected small and medium-size LFR conceptual designs by considering the four goal areas and eight specific goals of Generation IV.

The main features that the members have identified in order to achieve the GEN IV goals are discussed below. These features are based either on the inherent features of lead as a coolant or on the specific designs to be engineered for both LFR projects.

\section{V.A. Sustainability}

Resource utilization. Because lead is a coolant with very low neutron absorption and moderation, it is possible to maintain a fast neutron flux even with a large amount of coolant in the core. This allows an efficient utilization of excess neutrons. Reactor designs can readily achieve a breeding ratio of about 1 , long core life and a high fuel burn-up.

Waste minimization and management. A fast neutron flux significantly reduces waste generation, $\mathrm{Pu}$ recycling in a closed cycle being the condition recognized by GEN IV for waste minimization. The capability of the LFR systems to safely burn recycled minor actinides within the fuel will add to the attractiveness of the LFR.

\section{V.B. Economics.}

Life cycle cost. The cost advantage features of the LFR must include low capital cost, short construction duration and low fuel and generation costs. The economic utilization of MOX fuel in a fast spectrum has been already demonstrated in the case of the SFR, and no significantly different conclusion can be expected for the LFR.

Because of the favorable characteristics of molten lead, it will be possible to significantly simplify the LFR systems in comparison with the well known designs of the SFR, and hence to reduce its overnight capital cost, which is a major cost factor for the competitive generation of nuclear electricity.

A simple plant will be the basis for reduced capital and operating cost. A pool-type, low-pressure primary system configuration offers great potential for plant simplification.

The use of in-vessel Steam Generator Units (SGU's) and the consequent elimination of the intermediate circuit, typical of sodium technology, are expected to provide competitive generation of electricity in the LFR. This approach is possible because of the absence of vigorous chemical reactions between lead and water, although the SG tube rupture accident (i.e., pressure waves inside the SGU) must be considered in the design. The configuration of the reactor internals will be as simple as possible. The very low vapor pressure of molten lead should allow relaxation of the otherwise stringent requirements of gastightness of the reactor head and possibly allow the adoption of simple fuel handling systems.

Limiting the core outlet temperature will minimize corrosion by molten lead of candidate structural steels for the primary system. Considering that there will be no intermediate circuit to degrade the thermal cycle and that the expected core inlet temperature of about $400^{\circ} \mathrm{C}$ is relatively high, the adoption of a high-efficiency watersteam supercritical cycle is possible. Additionally, a supercritical carbon dioxide Brayton cycle energy conversion system can be considered.

Risk to capital. For small, transportable systems, a limitation to the risk to capital results from the small reactor size. In addition, and with particular relevance to the moderate- or large-size central station system, a reduction in the risk to capital results from the potential for removable/replaceable in-vessel components.

\section{V.C. Safety and Reliability}

Operation will excel in safety and reliability. Molten lead has the advantage of allowing operation of the primary system at low (atmospheric) pressure. A low dose to the operators can also be predicted, owing to its low vapor pressure and high capability of trapping fission products and high shielding of gamma radiation. In the case of accidental air ingress, in particular during refueling, any produced lead oxide can be reduced to lead by injection of hydrogen and the reactor operation safely resumed.

The moderate $\Delta \mathrm{T}$ between the core inlet and outlet temperatures reduces the thermal stress during transients, and the relatively low core outlet temperature minimizes the creep effects in steels.

Low likelihood and degree of core damage. It is possible to design fuel assemblies with fuel pins spaced further apart than in the case of sodium and this allows a large coolant fraction as in the case of the water reactor. This results in a moderate pressure loss through the core of about 1 bar, in spite of the high density of lead, with associated improved heat removal by natural circulation and the possibility of an innovative reactor layout such as installing the primary pumps in the hot collector to improve several aspects affecting safety.

Lead allows a high level of natural circulation of the coolant; this results in less stringent requirements for the 
timing of operations and simplification of the control and protection systems.

In case of leakage of the reactor vessel, the free level of the coolant can be designed to maintain a level that ensures the coolant circulation through, and the safe heat removal from the core. Any leaked lead would solidify without significant chemical reactions affecting the operation or performance of surrounding equipment or structures.

No need for off site emergency response. With highdensity lead as a coolant, fuel dispersion dominates over fuel compaction, making the occurrence of complex sequences leading to re-criticality less likely. In fact lead, with its higher density than oxide fuel and its natural convection flow, makes it difficult to lead to fuel aggregation with subsequent formation of a secondary critical mass in the event of postulated fuel failure.

\section{V.D. Proliferation Resistance and Physical Protection}

Unattractive route for diversion of weapon-usable material. The use of a MOX fuel containing MA increases proliferation resistance.

Physical Protection. The use of a coolant chemically compatible with air and water and operating at ambient pressure enhances Physical Protection. There is reduced need for robust protection against the risk of catastrophic events, initiated by acts of sabotage because there is a little risk of fire propagation and because of the passive safety functions. There are no credible scenarios of significant containment pressurization.

\section{CONCLUSIONS}

The LFR has been identified by the GIF as a technology with great potential to meet the needs for both remote sites and central power stations.

In the GEN IV technology evaluations, the LFR system is top-ranked in sustainability, proliferation resistance and physical protection. It is rated good in safety and economics. Safety is enhanced by the choice of a relatively inert coolant. The LFR is primarily envisioned for missions in electricity and hydrogen production and actinide management. Given its R\&D needs for fuel, materials, and corrosion control, the LFR system was estimated to be deployable by 2025 .

The Lead-cooled Fast Reactor Provisional Steering Committee (PSSC) was established in the year 2005 under the auspices of the GIF initiative with members from the USA, Japan, ROK and Euratom.
The approach of the GIF System Research Plan under development by the PSSC, is to consider two main technology objectives or tracks:

- a small, transportable system of 10-100 MWe, and

- a medium- or large-sized system rated at about $600 \mathrm{MWe}$.

Small-sized LFRs such as the SSTAR concept have the desired attributes for international deployment providing proliferation resistance, fissile self-sufficiency, autonomous load following, simplicity of operation and reliability, transportability, a high degree of passive safety, and a high plant efficiency improving economic competitiveness.

PEACER has been developed at NUTRECK in ROK as a large-scale, spent nuclear fuel transmutation and central power generation with multi-national controls for proliferation resistance. Both $3 \mathrm{D} \mathrm{CAD}$ and full-height loop tests have been conducted to verify the design soundness of PEACER-300 and PEACER-550 MWe, both cooled by the lead-bismuth eutectic. The PEACER design with a relatively low hot leg temperature $\left(400{ }^{\circ} \mathrm{C}\right)$ permits the use of existing code-certified materials such as Type 316L stainless steel and HT-9 so that a fast-track deployment is feasible.

The Russian Research and Development Institute of Power Engineering (NIKIET) with the BREST fast reactor concept, cooled by pure lead and the associated fuel cycle has indicated an innovative approach to nuclear waste management in a closed fuel cycle. A major step in favor of the LFR occurred when EURATOM decided to fund the ELSY project, in response to the call "Nuclear Waste Transmutation in Critical Reactors," to investigate the economic feasibility of using critical reactors for nuclear waste transmutation.

ELSY can rely on the important European contribution to the development of the LFR, which includes results from Russian ISTC projects, projects under the past FP5 [9-10] and ongoing FP6 [11] activities on ADS, and the Integrated Infrastructure Initiative (VELLA).

The larger-size 600 MWe ELSY is expected to be a simple, innovative reactor appealing to utilities for up-todate electric energy generation with reduced capital cost and construction time. In addition, the compactness of the primary system and the reduced footprint and height of the reactor building are attractive features. The reduced footprint is the consequence of elimination of the Intermediate Cooling System; the reduced elevation the result of the design approach of forced circulation and reduced-height components.

Based on the promising initial results, it is expected that ELSY can confirm the ambitious objectives of the designers and open a new phase of strong international support for LFR development and deployment.

Considering that significant commonality of R\&D can be found between the small, transportable system and the 
medium-or large-sized system of the two GEN IV approaches, the GIF SRP proposes coordinated research with a single demonstration facility that can serve the R\&D needs of both approaches. Full power operation of the Demo around the year 2018 - using to the greatest extent simple solutions, standard materials and operating at relatively low temperature, to reduce as much as possible the technological risks - could also justify the construction, at that date, of the first of a kind or industrial prototypes of SSTAR and ELSY and the industrial deployment at the horizon of 2020-2025 as foreseen in the GEN IV Roadmap.

\section{REFERENCES}

1. GIF-002-00, "Gen IV Technology Roadmap" December 2002.

2. System Research Plan for the Lead-cooled Fast Reactor (LFR) - Draft document of the LFR Provisional Steering Committee, March 2006.

3. Y. H. Yu, H. M. Son, I. S. Lee, K. Y. Suh, “Optimized Battery-Type Reactor Primary System Design Utilizing Lead," Paper 6148, Proceedings of the International Congress on Advances in Nuclear Power Plants (ICAPP), Reno, NV, USA, June 4-8, 2006.

4 I.S. Hwang, "A Sustainable Regional Waste Transmutation System: P E A C E R, Plenary Invited Paper, ICAPP '06, Reno, NV, U.S.A., June 4-6, 2006.

5. W. J. Kim, T. W. Kim, M. S. Sohn, K. Y. Suh, "Supercritical Carbon Dioxide Brayton Power Conversion Cycle Design for Optimized Battery-Type Integral Reactor System," Paper 6142, Proceedings of the International Congress on Advances in Nuclear Power Plants (ICAPP), Reno, NV, USA, June 4-8, 2006.

6. A. V. Zrodnikov, G. I. Toshinsky, O. G. Komlev, Yu. G. Dragunov, V. S. Stepanov, N. N. Klimov, I. I. Kpytov, and V. N. Krushelnitsky, "Use of Multi-Purpose Modular Fast Reactors SvBR-75/100 in Market Conditions," Paper 6023, 2006 Congress on Advances in Nuclear Power Plants (ICAPP '06), Reno, Nevada, USA, June 4-8, 2006

7. E. O. Adamov and V. V. Orlov, A. Filin, Final report on the ISTC Project \#1418: "Naturally Safe LeadCooled Fast Reactor for Large Scale Nuclear Power", Moscow 2001

8. L. Cinotti, H. Aït Abderrahim, G. Benamati, C. Fazio,
J. Knebel, G. Locatelli, S. Monti, C. F. Smith, K. Suh "Lead-Cooled Fast Reactor", FISA 2006, Luxembourg 13-16 March 2006.

9. L. Cinotti et al., "The eXperimental Accelerator Driven System (XADS) Designs in the EURATOM 5th Framework Programme", Journal of Nuclear Materials, 335, 148-155, 2004.

10. A.Aiello, A Azzati, G. Benamati, A. Gessi, B. Long, G. Scadozzo, "Corrosion behaviour of steels in flowing LBE at low and high oxygen concentration" Journal of Nuclear Materials, 335, 169-173, 2004.

11. C. Fazio, A. Alamo, A. Almazouzi, D. Gomez-Briceno, F. Groeschel, F. Roelofs, P. Turroni and J. U. Knebel, "Assessment of Reference structural materials, heavy liquid metal technology and thermal-hydraulics for European waste transmutation ADS", Proceedings of GLOBAL, Tsukuba, Japan, Oct 9-13, 2005. 